\title{
A quantitative study of poplar plantation situation in four Iran provinces
}

\section{Majid Azizi *(D), Mohammad Mehdi Faezipour*, Ali Bayatkashkoli **iD}

* College of Agriculture and Natural Resources, University of Tehran,

Faculty of Natural Resources, Wood and Paper Sciences and Technology Department

16th Azar St., Enghelab Sq., Tehran, Iran

** Faculty of Natural Resources, University of Zabol, Zabol, Iran

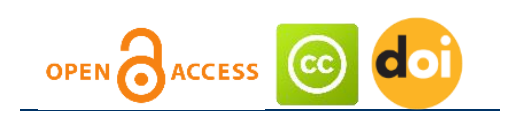

Article history:

Received: December 22, 2020

1st Revision: February 10, 2020

Accepted: April 12, 2020

JEL classification:
013
Q13
Q18

\section{DOI:}

10.14254/jems.2020.5-1.2

\begin{abstract}
Poplars, a fast-growing species, enjoy a high significance in Iran's industry. So far, information on poplar plantation, such as area, volume, and harvest, has been obtained by nonscientific and poor methods. A few studies have been conducted to recognize capability of poplar plantation about area, volume, harvest, distribution, and species in three high efficient provinces, i.e., Eastern/ Azerbaijan, Zanjan, Kermanshah, and Ardabil. A Cluster sampling a standard sampling method for conducting similar researches was selected, consisting of two phases. In the first phase we collected library information and half-open interview from villagers. In the second phase field measurement in the villages of these four provinces was considered. Obtained information from field measurement was erected poplar volume, cultivated poplar area, prevalent species and estimating volume via volume and weight tables. Results obtained from the present study indicate that average annual utilization volume of four provinces was $172628.84 \mathrm{~m}^{3}$, with an average error of 14.19 percent.
\end{abstract}

Keywords: poplar plantation area, field measurement, harvest value, clustered sampling.

\section{Introduction}

Considering wood product needs of the country and disability in producing sufficient wood from northern forests, developing the poplar plantation area is inevitable in Iran. But a number of factors not only have halted the development of poplar plantation in different regions but also severely caused poplar cutting and changed these lands into agriculture land. Poplar wood volume

Corresponding author: Majid Azizi

E-mail: mazizi@ut.ac.ir

This open access article is distributed under a Creative Commons Attribution (CC-BY) 4.0 license. 
production in 1993 was more than two million $\mathrm{m}^{3}$. After 11 years in 2003 statistics for planting forests to produce wood shows a small increase/ (i.e., from $2000000 \mathrm{~m}^{3}$ to $2500000 \mathrm{~m}^{3}$ per year). Changes of area, standing volume and annual harvest can partly determine the development of wood products in the future. Meanwhile, with identifying different species of poplar in different regions, the possibility of optimal use of this wood material for various industrial applications will be provided.

Various industries, i.e., wood industry, layers of veneer and plywood, sawmill (for carpentry wood production and scaffolding boards, electricity beams, telecommunications, and mining paraffin) and paper, use poplar wood in Iran. Poplar wood satisfies Iran's quickly increasing industry needs and causes slow destruction of forests.

Since poplars as a wood source have great importance for use in pulp and paper industries, it is necessary to create an appropriate database for identifying this important wood material in terms of area, volume, distribution, species, and harvest. However, up to date, access to such information and statistics for researchers and industrialists for industrial applications has met great difficulty.

In developed countries, this database regarding wood material is accessible, up to date and low cost. In Iran in spite of being rich and different regions of poplar wood there is not appropriate database to obtain easy and quick information in this regard, hence generation of database is very important and vital for the country.

Therefore, in this study, to answer some of these needs, the status of properties of poplar wood in four high-capability provinces has been studied and analyzed.

Some studies have been conducted on the importance of poplar and its applications. Balatinecz and Kretschmann (2001) specified that the use of round poplar wood in 1989 was four times than that in 1975. Its applications include pulp, lumber, pressed boards, insulation boards, cover, and veneer layers, wood composite material (chip board and wafer board), structural composite lumber (laminated lumber), pallets, furniture, fruit baskets, and shelves. The consumption of poplar wood is more than its plantation. Most research has been focused on breeding of poplar trees in terms of growth rate, appearance, compatibility, and resistance to dryness, while few on its modified wood. Breeding poplars compared to local poplars have more similar mechanical properties, faster growth, and more young wood. Subtle features and filtering of paper made from poplar is great and is suitable for printing paper. Poplar wood has the potential of decay, discoloration, and disadvantages of wood drying (especially those with wet holes). Davision and Riggs (2004) asserted that consumption/application of poplar trees, such as wood and paper production, is very extensive. Since the commercial value of its pulp decreased, new applications of modified poplar wood have been developed, such as furniture framework, pallets, decorative wood, the core materials covered with a coating, layer boards, chipboards, directional boards, wafer, and laminated lumber.

Mills (2001) found that demand for wood material is affected by area change in planting forest trees, their operation, and delivery, increased consumption of wood and the way of management. In the future wooden buildings will be more and thus, investment in forests will increase and the need for wood products will increase. Softwood lumber production in 1990 decreased more than half. After that, in 1996, utilization of agricultural wood became more and more. Therefore, it is expected to increase investment for production of wood. Amount of forest product manufacturing industries in Turkey in the period from 1990 to 1999 has increased largely and reached important business objectives. Various forest products are exported and the number of countries that Turkey has trade relations with them has increased, a total of 139 different countries with regarding business till 1999. Turkey's total production of forest products includes wood, lumber, frame wood, wood coating, pipe cutting and packing material, furniture, production of non-wood forest products and building materials and structures (Huseyin and Kurtoglu, 2001). Investigation of the market of small-diameter poplar wood and wood products in Iran shows that dependence of producers of wood products on poplar wood has greatly expanded and hence, any fluctuation, problems, and potential changes in the poplar wood market conditions are transferred to wood products market (Bayatkashkooli, 2006).

The aim of the study is to identify the resources and capabilities of different regions of the country in terms of poplar plantations and to provide comprehensive information to researchers and investors for proper utilization of this valuable species. In order to achieve this goal, characteristics such as the way of distribution, area, volume, harvest and species of poplar wood in three provinces, i.e., Eastern Azerbaijan, Zanjan, Ardabil, and Kermanshah, were calculated and analyzed.

\section{Material and methods}

Based on previous studies, four provinces, i.e., Eastern Azerbaijan Zanjan, Ardabil and Kermanshah were selected as research fields, due to their high capability of poplar plantation area, many factories or workshops, as well as high consumption, production, and export of poplar wood. Geographical map of the provinces is presented in Fig. 1. A two-stage cluster sampling method was 
used. In the first phase collecting library information and half-open interviews in rural areas were considered and in the second phase field survey was conducted in villages of the four provinces. Hence a general list of the towns, villages each province were taken, based on information in Iran Oasis Records Book Population and Housing Census Book of Iran (2007). Villages of these provinces were classified in six different groups, i.e., flat, mountainous, plain and mountainous, plain and forest, mountain forest and the other. To represent the whole community about 30 villages in different cities of a province were selected randomly. The number of the selected villages in each city were compatible with total of villages of the cities. Based on obtained addresses from governors of each province regarding selected regions, telephone interview was carried out. Then the necessary adjustments were carried out in selected villages. Information such as area and amount of the annual harvest was collected in each village. The second phase includes selecting villages for the field survey. Six villages from 30 villages were selected randomly from each province in order to carry out field survey.

Data collected from the field survey include: 1) cultivated area of poplar, 2) standing poplar volume, 3) dominant species in each region and 4) measurement of the diameter, height, and estimation of the volume by volume and weight tables. The number of poplar trees in each hectare, average diameter and height of cut and standing poplar for calculating area, volume and weight were determined. Criteria for measurements and calculations were high trees with a diameter of $10 \mathrm{~cm}$. The volume was obtained by poplar volume tables calculated by Bagheri (1997) for poplars in Iran and by Mirsadeghi and Hedayati (1988) for poplars in Turkey. To calculate the weight, the special weight calculated by Bagheri (1997) for Iran poplars was selected.

According to information obtained from the interview and field survey, this information can be extended to the whole province with a definite error percentage. If we multiply average of the cultivated area of the villages in total number of the villages of each province, result cultivated area of each province and regarding annual harvest volume is the same rule.

To determine the sampling error, the field survey was considered as the base of the work. The error percentage of calculation was obtained from Eq. 1.

$$
\mathrm{EP}=A_{\mathrm{I}}-A_{\mathrm{F}} / A_{\mathrm{F}} \times 100
$$

where EP is the error percentage (an area or annual harvest), $A_{\mathrm{I}}$ the area or annual harvest of interview and $A_{\mathrm{F}}$ the area or annual harvest of field survey.

\section{Results}

Based on information gathered from Iran Oasis Records Book (2007), the total number of rural villages of East Azarbaijan Province was determined as 2794, 1101 for Zanjan, 2276 for Ardabil and 2797 for Kermanshah. According to the field survey, the dominant species in East Azarbaijan was shall (Populus nigra) and some modified poplar.

The dominant species of poplar in Zanjan was locally named Raji (Populus nigra) In Ardabil Province the dominant species these modified poplars were more than other Hybrid species such as Tabrizi (Populus nigra) and in Kermanshah dominant species were Tabrizi (Populus nigra).

The number of poplar trees per hectare varied among different provinces. The density of poplar trees in Ardabil was greater compared to the other three provinces. The number of trees of the four provinces on the basis of field survey is presented in Table 1. Volume and average weight of each of the standing poplar trees were calculated based on their average diameter and height by using poplar volume tables (Davision and Riggs, 2004) and average density of poplars (equal 526 $\mathrm{kg} / \mathrm{m}^{3}$; Bagheri, 1997) for each province. Table 2 shows the average height, diameter, volume and average weight of standing trees by using different methods. Similarly, the average volume and weight of each of the cut trees for each province were calculated, which are shown in Table 3.

The area of cultivated poplar plantation and volume and weight of standing poplar trees of each province are listed in Table 4 . As can be seen from this Table, the area of poplar plantation in Zanjan (6343.58 ha) was more than that of the other three provinces $(2031.945,5493.427$ and 3288.403 ha).

The volume and weight of the annual harvest of poplar in the four provinces, according to the interview were illustrated in Table 5. The cultivated area and the annual harvest of poplar, along with the percentage of possible errors in their estimation for each province, were listed in Tables 6-9.

\section{Discussion}

The results of Tables 6-8 show that in three poplar rich provinces, i.e., Zanjan, Eastern Azerbaijan, Ardabil and Kermanshah, the area of poplar plantation is 4712.69, 2625.183, 6705.57 and 3995.714 ha, respectively; and the percentage error obtained on the basis of a comparison 
between two methods of interview and field survey was $25.7 \%, 29.2 \%, 22 \%$, and $21.5 \%$, respectively. The annual harvest volume in four provinces was $25506.8 \mathrm{~m}^{3}$ for Zanjan, $46233.54 \mathrm{~m}^{3}$ for Eastern Azerbaijan, $74991.1 \mathrm{~m}^{3}$ for Ardabil and $25891.4 \mathrm{~m}^{3}$ for Kermanshah; and their percentage errors were $4.6 \%, 9.7 \%, 15.27 \%$, and $27.2 \%$, respectively, indicating that in both cases obtained error is relatively acceptable.

The percentage errors were merely calculated for the area and volume of the annual harvest. In the case of the area of poplar plantation Ardabil Province achieved a higher priority than the other three provinces (6705.57 ha and $74991.1 \mathrm{~m}^{3}$ ) that indicate higher poplar plantation area in this province. Report of Country Forests and Rangelands Organization (1992) shows that the area of poplar plantation of the whole country was 150,000 ha, while that of four provinces was 26969 ha; accordingly, these four provinces had about $18 \%$ of the total amount of poplar plantation of the whole country (Wood Industry Technical Office. 1992).

On the other hand, based on the statistics presented on the area and rank of the forestry competition in 2003, the total forestry area in Iran has been estimated at 425645 hectares (Iran Statistical Center, 2002)).

If fifty percent of the above mentioned area, poplar plantation is assumed, then it would be two hundred thousand hectares of poplar plantation. The comparison is based on the statistics in this reference (.Iran Statistical Center, 2002). In this case, the level of poplar production (18039) will be about ten percent of the total poplar area

Indicating an 8 percent decline in poplar populations in these four provinces. One of the main reasons for the decline in a poplar plantation in these four provinces over the past two decades is the establishment of new wood and paper mills near these provinces, which are major consumers of poplar wood but have not been re-planted after harvest. On the other hand, given the good conditions of Zanjan province for poplar cultivation and the greater motivation of poplar cultivators and the support provided by government institutions in the province, we are seeing an increase in the level of poplar cultivation in the province over the past two decades. According to Forestry Organization statistics in 1992, the poplar plantation area in Zanjan province was 1575 hectares, while according to the current study, the poplar area reached 4712 hectares, indicating a threefold increase.

In the other three provinces, the level of poplar cultivation has declined sharply over the past two decades. The use of modified poplar trees with higher diameter and height is one of the strengths of poplar cultivation in Zanjan province. Whereas in the Eastern Azarbaijan province, the old process of poplar cultivation is still used and there is less interest in poplar cultivation with modified poplar. Zanjan province can be considered as a suitable model for other poplar provinces in terms of poplar cultivation and its optimal utilization.

The poplar harvest in the four provinces is about 172600 cubic meters and the total poplar area is 17900 hectares, which would be 9.6 cubic meters per hectare. On the other hand, 5, 17, 11 and 6 cubic meters per hectare of wood were harvested in Zanjan, Azarbayjan, Ardabil and Kermanshah provinces, respectively.

Currently, about 750000 cubic meters of wood is used for industrial production from northern forests of Iran which due to the impossibility of harvesting it should be obtained from other sources. If the current process of poplar cultivation is maintained, not only this amount of industrial consumption can be provided through poplar cultivation, but also other local consumption and production of wood products can easily be financed by the development of poplar plantation. The use of agricultural wastes and waste also reduces the need for imports, in this case, to meet the wood industry needs of the country we only need 10 to 15 percent of imports (relative to total wood demand) which is negligible. If poplar harvesting continues with the present conditions and the necessary support is provided to poplar farmers, then poplar cultivation would be a great source of supply for the wood and paper industries in the present situation, which are facing a severe shortage of industrial wood.

In the case of poplars, the rate of harvesting as forests does not follow the continuous principle, and this is subject to market conditions in terms of price and demand for poplar wood. Nowadays most of the farmers are traditionally planting poplar and if the price of poplar rises, it is immediately harvested and marketed, so poplar harvest does not correspond to its annual growth rate.

This indicates that if relevant government agencies and the wood and paper industries are planning to set up new units or develop existing units, it is necessary to establish a link between wood industries managers and poplar farmers to reduce the risk of raw material shortages. This relationship can be achieved through the financial support of poplar farmers and the timely purchase of the poplar at affordable prices.

Proper planning in the future should focus on the cultivation of modified poplars in poplar areas such as Zanjan province in order to cope with the rest of the northern forests so that it can provide the needed domestic wood. 


\section{Conclusions}

Field survey determined that the dominant species in four provinces is Populus nigra. The area of poplar plantation in Zanjan, Eastern Azerbaijan, Ardabil and Kermanshah, is 4712.69, 2625.183, 6705.57 and 3995.714 ha, respectively. The calculated standing volume of poplar plantation in these four provinces were $10638461,3169946,5734121$ and $77518.66 \mathrm{~m}^{3}$, respectively. The annual harvest volume was $25506.88 \mathrm{~m}^{3}$ in Zanjan, $46233.54 \mathrm{~m}^{3}$ in Eastern Azerbaijan, $74991.1 \mathrm{~m}^{3}$ in Ardabil and $25891.4 \mathrm{~m}^{3}$ in Kermanshah.

The total volume of standing poplar in three provinces was approximately 19,620,046.66 $\mathrm{m}^{3}$, indicating a decrease of standing timber volume compared to the past decade. Zanjan can be a suitable poplar plantation pattern for other poplar provinces due to the use of modified poplar trees with higher diameter and height.

Based on the results in these four provinces on average about $9.6 \mathrm{~m}^{3}$ per ha wood has been harvested.

\section{Appendix A. Supplementary material}

Supplementary data associated with this article can be found, in the online version, at https://doi.org/10.14254/jems.2020.5-1.2

\section{Acknowledgment}

The authors would like to acknowledge the centers of Excellence University of Tehran for financial supports.

\section{Conflict of Interest}

The author declares that he has no conflict of interest.

\section{Citation information}

Azizi, M., Faezipour, M. M., \& Bayatkashkoli, A. (2020). A quantitative study of poplar plantation situation in four Iran provinces. Economics, Management and Sustainability, 5(1), 17-28. doi:10.14254/jems.2020.5-1.2.

\section{References}

Bagheri, R. (1997). Procurement of weight - volume tables for local poplars of Zanjanrood area. Pazhoohesh and Sazandegi, 36 (in Persian).

Bayatkashkooli, A. (2006). Study of poplar low diameter wood market and wood products in Iran. J Iran Nat Res, 59(4), 963-980 (in Persian).

Balatinecz, J., \& Kretschmann, D. (2001). Properties and utilization of poplar wood, in poplar culture in North America, Part A, Chapter 9, NRC research press, National research council of Canada, Ottawa, ON KIA OR6, Canada, 277-291.

Davison, J., \& Riggs, W. (2004). Hybrid poplar production 1998-2003 in Eureka and Churchill Counties. In University of Nevada Cooperative Extension, Fact Sheet 05-25.

Iran Oasis Records Book. (2007). Population and housing censuses by country. Retrieved from http://en.wikipedia.org/wiki/Population_and_housing_censuses_by_country\#Iran.

Iran Statistical Center. (2002). Statistical Yearbook of Iran. Statistical Center of Iran, Affiliated to Management and Planning Organization, Tehran.

Koç, K. H., Kurtoğlu, A., \& Baki, A. K. S. U. (2001). Regional and international structure of the Turkish forest products foreign trade. In Forest Products Society Annual Meeting in Baltimore.

Mills, J. R. (2001). Outlook for the USA. Timber inventory: management, growth and harvest, forest products society 55th Annual Meeting, Baltimore, Maryland, USA. 
Mirsadeghi, M., \& Hedayati, M. (1988). Make a profit in poplar cultivation systems of Turkey. Forests and Pastures Organization (In Persian).

Wood Industry Technical Office. (1992). Iranian poplars funds of forest revitalization and industry development. Forests and pastures organization (In Persian). 


\section{Appendix}

Table 1: Number of trees in specified area of Zanjan, Eastern Azerbaijan, Ardabil and Kermanshah provinces

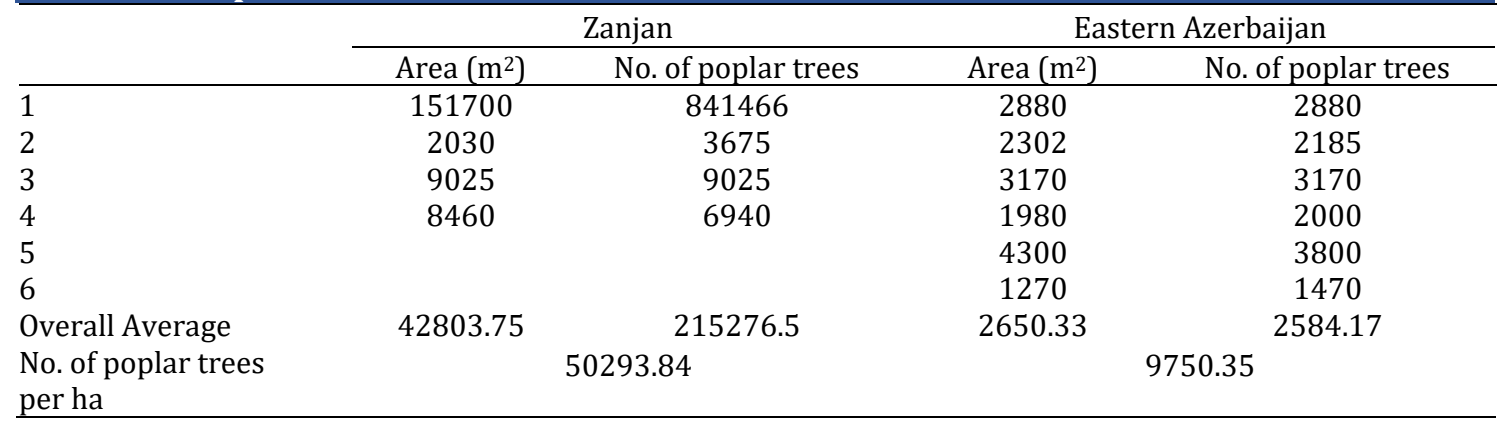

\section{Table 1: (Continued)}

\begin{tabular}{|c|c|c|c|c|}
\hline & \multicolumn{2}{|c|}{ Ardabil } & \multicolumn{2}{|c|}{ Kermanshah } \\
\hline & Area $\left(\mathrm{m}^{2}\right)$ & No. of poplar trees & Area $\left(\mathrm{m}^{2}\right)$ & No. of poplar trees \\
\hline$\overline{1}$ & 9500 & 16800 & 2100 & 150 \\
\hline 2 & 161500 & 50640 & 15600 & 335 \\
\hline 3 & 1200 & 65 & 16240 & 1100 \\
\hline 4 & 19600 & 10600 & 525690 & 11978 \\
\hline 5 & 5800 & 3130 & 520 & 50 \\
\hline 6 & 156600 & 154880 & & \\
\hline Overall average & 59033.33 & 39352.5 & 112030 & 2722.6 \\
\hline $\begin{array}{l}\text { No. of poplar trees } \\
\text { per ha }\end{array}$ & \multicolumn{2}{|c|}{6666.149} & \multicolumn{2}{|c|}{243.024} \\
\hline
\end{tabular}


Table 2: Average diameter and height of standing poplar trees and their average volume and weight

\begin{tabular}{|c|c|c|c|c|}
\hline & \multicolumn{2}{|c|}{ Zanjan } & \multicolumn{2}{|c|}{ Eastern Azerbaijan } \\
\hline & Height $(\mathrm{m})$ & Diameter $(\mathrm{cm})$ & Height $(\mathrm{m})$ & Diameter $(\mathrm{cm})$ \\
\hline 1 & 9.5 & 27.5 & 10 & 23 \\
\hline 2 & 11.33 & 18.5 & 16 & 17 \\
\hline 3 & 12 & 25.33 & 15 & 18 \\
\hline 4 & 13 & 22.5 & 11 & 19 \\
\hline 5 & 12.66 & 23.67 & 15 & 18 \\
\hline 6 & 11 & 33.33 & 13 & 23 \\
\hline 7 & 13.67 & 23.33 & 15 & 19 \\
\hline 8 & 10.33 & 21.67 & 11 & 24 \\
\hline 9 & 14.33 & 20.66 & 12 & 22 \\
\hline 10 & 10 & 18 & 14 & 22 \\
\hline 11 & 13 & 32.5 & 11 & 23.50 \\
\hline 12 & 15.33 & 29 & 12 & 20 \\
\hline 13 & 14 & 17.5 & 11 & 19 \\
\hline 14 & 12.66 & 23.67 & 13 & 23 \\
\hline 15 & 9.33 & 10 & 12 & 25 \\
\hline Total average & 12.14 & 23.14 & 12.73 & 21.03 \\
\hline Rounding numbers & 12 & 23 & 13 & 21 \\
\hline Poplar volume ${ }^{1}\left(\mathrm{~m}^{3}\right)$ & \multicolumn{2}{|c|}{0.228} & \multicolumn{2}{|c|}{0.207} \\
\hline Poplar volume ${ }^{2}\left(\mathrm{~m}^{3}\right)$ & \multicolumn{2}{|c|}{0.098} & \multicolumn{2}{|c|}{0.113} \\
\hline Average of volume $\left(\mathrm{m}^{3}\right)$ & \multicolumn{2}{|c|}{0.163} & \multicolumn{2}{|c|}{0.16} \\
\hline Weight ${ }^{1}(\mathrm{~kg})$ & \multicolumn{2}{|c|}{119.928} & \multicolumn{2}{|c|}{108.882} \\
\hline Weight $^{2}(\mathrm{~kg})$ & \multicolumn{2}{|c|}{51.548} & \multicolumn{2}{|c|}{59.438} \\
\hline Average of weight (kg) & \multicolumn{2}{|c|}{85.738} & \multicolumn{2}{|c|}{84.16} \\
\hline
\end{tabular}

Note: density is 526.1 means poplar volume and weight based on Bagheri's method; 2 means poplar volume and weight based on Hedayati and Mirsadeghi's method. The same comment applies to the following tables.

\section{Table 2: (Continued)}

\begin{tabular}{|c|c|c|c|c|}
\hline & \multicolumn{2}{|c|}{ Ardabil } & \multicolumn{2}{|c|}{ Kermanshah } \\
\hline & Height (m) & Diameter $(\mathrm{cm})$ & Height (m) & Diameter $(\mathrm{cm})$ \\
\hline 1 & 11 & 20 & 8 & 19 \\
\hline 2 & 10 & 22 & 9 & 18 \\
\hline 3 & 12 & 22 & 10 & 20 \\
\hline 4 & 12 & 25 & 8 & 16 \\
\hline 5 & 11 & 22 & 11 & 20 \\
\hline 6 & 11 & 25 & 12 & 22 \\
\hline 7 & 10 & 18 & 12 & 21 \\
\hline 8 & 12 & 25 & 10 & 16 \\
\hline 9 & 15 & 28 & 10 & 18 \\
\hline 10 & 13 & 26 & 11 & 20 \\
\hline 11 & 11 & 23 & 12 & 19 \\
\hline 12 & 14 & 24 & 10 & 15 \\
\hline 13 & 12 & 24 & 10 & 19 \\
\hline 14 & 13 & 25 & 8.0 & 16 \\
\hline 15 & 14 & 20 & 11 & 17 \\
\hline Total average & 12.066 & 23.266 & 10.133 & 18.4 \\
\hline Rounding numbers & 12 & 23 & 10 & 18 \\
\hline Poplar volume ${ }^{1}\left(\mathrm{~m}^{3}\right)$ & \multicolumn{2}{|c|}{0.228} & \multicolumn{2}{|c|}{0.105} \\
\hline Poplar volume ${ }^{2}\left(\mathrm{~m}^{3}\right)$ & \multicolumn{2}{|c|}{0.098} & \multicolumn{2}{|c|}{0.089} \\
\hline Average of volume $\left(\mathrm{m}^{3}\right)$ & \multicolumn{2}{|c|}{0.163} & \multicolumn{2}{|c|}{0.097} \\
\hline Weight $^{1}(\mathrm{~kg})$ & \multicolumn{2}{|c|}{119.928} & \multicolumn{2}{|c|}{55.23} \\
\hline Weight $^{2}(\mathrm{~kg})$ & \multicolumn{2}{|c|}{51.548} & \multicolumn{2}{|c|}{46.814} \\
\hline Average of weight (kg) & \multicolumn{2}{|c|}{85.738} & \multicolumn{2}{|c|}{51.022} \\
\hline
\end{tabular}


Table 3: Average diameter and height of cut poplar trees and their average volume and weight

\begin{tabular}{|c|c|c|c|c|}
\hline & \multicolumn{2}{|c|}{ Zanjan } & \multicolumn{2}{|c|}{ Eastern Azerbaijan } \\
\hline & Height $(\mathrm{m})$ & Diameter $(\mathrm{cm})$ & Height (m) & Diameter $(\mathrm{cm})$ \\
\hline 1 & 11 & 26 & 12 & 15 \\
\hline 2 & 12 & 20 & 12 & 22 \\
\hline 3 & 14 & 27 & 15 & 30 \\
\hline 4 & 10 & 21 & 12 & 12 \\
\hline 5 & 15 & 28 & 16 & 35 \\
\hline 6 & 11 & 29 & 13 & 18 \\
\hline 7 & 13 & 22 & 18 & 26 \\
\hline 8 & 13 & 23 & 14 & 21 \\
\hline 9 & 12 & 23 & 17 & 32 \\
\hline 10 & 9 & 21 & 12 & 18 \\
\hline 11 & 14 & 30 & 14 & 18 \\
\hline 12 & 16 & 32 & 16 & 20 \\
\hline 13 & 13 & 25 & 13 & 25 \\
\hline 14 & 14 & 24 & 15 & 35 \\
\hline 15 & 12 & 18 & 17 & 23 \\
\hline Total average & 12.6 & 24.6 & 14.4 & 23.33 \\
\hline Rounded numbers & 13 & 25 & 14 & 23 \\
\hline Poplar volume ${ }^{1}\left(\mathrm{~m}^{3}\right)$ & \multicolumn{2}{|c|}{0.31} & \multicolumn{2}{|c|}{0.273} \\
\hline Poplar volume ${ }^{2}\left(\mathrm{~m}^{3}\right)$ & \multicolumn{2}{|c|}{0.095} & \multicolumn{2}{|c|}{0.113} \\
\hline Average of volume $\left(\mathrm{m}^{3}\right)$ & \multicolumn{2}{|c|}{0.2025} & \multicolumn{2}{|c|}{0.193} \\
\hline Weight $^{1}(\mathrm{~kg})$ & \multicolumn{2}{|c|}{163.06} & \multicolumn{2}{|c|}{143.598} \\
\hline Weight $^{2}(\mathrm{~kg})$ & \multicolumn{2}{|c|}{49.97} & \multicolumn{2}{|c|}{59.438} \\
\hline Average of weight $(\mathrm{kg})$ & \multicolumn{2}{|c|}{106.515} & \multicolumn{2}{|c|}{101.518} \\
\hline
\end{tabular}

Note: density is 526. 1 means poplar volume and weight based on Bagheri's method; 2 means poplar volume and weight based on Hedayati and Mirsadeghi's method. The same comment applies to the following tables.

\section{Table 3 (Continued)}

\begin{tabular}{|c|c|c|c|c|}
\hline & \multicolumn{2}{|c|}{ Ardabil } & \multicolumn{2}{|c|}{ Kermanshah } \\
\hline & Height $(\mathrm{m})$ & Diameter $(\mathrm{cm})$ & Height $(\mathrm{m})$ & Diameter $(\mathrm{cm})$ \\
\hline 1 & 12 & 23 & 9 & 20 \\
\hline 2 & 12 & 22 & 10 & 21 \\
\hline 3 & 12 & 25 & 11 & 20 \\
\hline 4 & 13 & 28 & 8 & 18 \\
\hline 5 & 11 & 22 & 11 & 16 \\
\hline 6 & 12 & 25 & 12 & 20 \\
\hline 7 & 13 & 25 & 9 & 17 \\
\hline 8 & 14 & 27 & 11 & 18 \\
\hline 9 & 15 & 30 & 9 & 18 \\
\hline 10 & 12 & 26 & 11 & 20 \\
\hline 11 & 12 & 24 & 10 & 16 \\
\hline 12 & 13 & 24 & 9 & 15 \\
\hline 13 & 13 & 25 & 10 & 19 \\
\hline 14 & 14 & 28 & 9 & 17 \\
\hline 15 & 13 & 27.5 & 11.5 & 20 \\
\hline Total average & 12.733 & 25.433 & 10.066 & 18.333 \\
\hline Rounded numbers & 13 & 25 & 10 & 18 \\
\hline Poplar volume ${ }^{1}\left(\mathrm{~m}^{3}\right)$ & \multicolumn{2}{|c|}{0.31} & \multicolumn{2}{|c|}{0.105} \\
\hline Poplar volume ${ }^{2}\left(\mathrm{~m}^{3}\right)$ & \multicolumn{2}{|c|}{0.095} & \multicolumn{2}{|c|}{0.089} \\
\hline Average of volume $\left(\mathrm{m}^{3}\right)$ & \multicolumn{2}{|c|}{0.2025} & \multicolumn{2}{|c|}{0.097} \\
\hline Weight $^{1}(\mathrm{~kg})$ & \multicolumn{2}{|c|}{163.06} & \multicolumn{2}{|c|}{55.23} \\
\hline Weight $^{2}(\mathrm{~kg})$ & \multicolumn{2}{|c|}{49.97} & \multicolumn{2}{|c|}{46.814} \\
\hline Average of weight $(\mathrm{kg})$ & \multicolumn{2}{|c|}{106.515} & \multicolumn{2}{|c|}{51.022} \\
\hline
\end{tabular}


Table 4: Cultivated area, volume and weight of standing poplar in four provinces based on interview method

\begin{tabular}{lccc}
\hline Zanjan & Area (ha) & Volume $0.163\left(\mathrm{~m}^{3}\right)$ & /Weight 85.738 $\mathrm{kg}$ \\
Average & 5.76 & 9662.44 & 24646350.7 \\
Total & 6343.58 & 10638461 & 27135632125 \\
Eastern Azerbaijan & Area (ha) & Volume $0.16\left(\mathrm{~m}^{3}\right)$ & Weight $84.16 \mathrm{~kg}$ \\
Average & 0.727253 & 1134.555 & 596775.8452 \\
Total & 2031.945 & 3169946 & 1667391711 \\
Ardabil & Area (ha) & Volume $0.163\left(\mathrm{~m}^{3}\right)$ & Weight $85.738 \mathrm{~kg}$ \\
Average & 2.413632 & 2519.385 & 1325196.606 \\
Total & 5493.427 & 5734121 & 3016147476 \\
Kermanshah & Area (ha) & Volume $0.097\left(\mathrm{~m}^{3}\right)$ & Weight $51.022 \mathrm{~kg}$ \\
Average & 1.175689 & 27.71493 & 14578.05349 \\
Total & 3288.403 & 77518.66 & 40774815.61 \\
\hline
\end{tabular}

\begin{tabular}{|c|c|c|c|}
\hline Zanjan & Annual harvest (ton) & Volume $0.2025\left(\mathrm{~m}^{3}\right)$ & Weight $106.515 \mathrm{~kg}$ \\
\hline Average & 12.146146 & 23.45080645 & 12335.12 \\
\hline Total & 13372.9067 & 25819.3379 & 13580972 \\
\hline Eastern Azerbaijan & Annual harvest (ton) & Volume $0.193\left(\mathrm{~m}^{3}\right)$ & Weight $101.518 \mathrm{~kg}$ \\
\hline Average & 11.4453358 & 21.75919355 & 11445.34 \\
\hline Total & 31978.2682 & 60795.18677 & 31978268 \\
\hline Ardabil & Annual harvest (ton) & Volume $0.2025\left(\mathrm{~m}^{3}\right)$ & Weight $106.515 \mathrm{~kg}$ \\
\hline Average & 19.5952095 & 37.25325 & 19595.21 \\
\hline Total & 44598.6968 & 84788.397 & 44598697 \\
\hline Kermanshah & Annual harvest (ton) & Volume $0.097\left(\mathrm{~m}^{3}\right)$ & Weight $51.022 \mathrm{~kg}$ \\
\hline Average & 3.63737484 & 6.91516129 & 3637.375 \\
\hline Total & 10173.7374 & 19341.70613 & 10173737 \\
\hline
\end{tabular}

\begin{tabular}{lcc}
\multicolumn{3}{l}{ Table 6: Cultivated area and value of annual harvest of poplar, along with potential error } \\
percentage based on the results of field survey and interview methods in Zanjan Province \\
\hline Village & Area (ha) & Annual harvest (ton) \\
\hline Sookariz & 16.73 & 32.48 \\
Sohravard & 0.073 & 5.858 \\
Ag & 0.179 & 2.769 \\
Karsaf & 0.137 & 5.219 \\
Average & 4.28 & 11.583 \\
Total & 4712.692 & 12753.44 \\
Error percentage & $25.709 \%$ & $4.632 \%$ \\
\hline
\end{tabular}

Note: the total number of villages of Zanjan equals 1101

$\begin{aligned} & \text { Table 7: Cultivated area and value of annual harvest of poplar, along with potential error } \\
& \text { percentage based on the results of field survey and interview methods in Eastern } \\
& \text { Azerbaijan Province }\end{aligned}$
\begin{tabular}{lcc} 
Village & Area (ha) & Annual harvest (ton) \\
\hline Pirsoltan Bostanabad & 1.047 & 4.466 \\
Dilar Ahar & 0.794 & 2.436 \\
Achachi Miyaneh & 1.152 & 3.654 \\
Zangi Shabestar & 0.727 & 4.466 \\
Doozal Jolfa & 1.381 & 21.318 \\
Golestanolia Maragheh & 0.534 & 13.298 \\
Average & 0.939 & 8.273 \\
Total & 2625.183 & 23116.77 \\
Error percentage & $29.195 \%$ & $27.711 \%$
\end{tabular}

Note: the total number of villages of Eastern Azerbaijan equals 2794 
Table 8: Cultivated area and value of annual harvest of poplar, along with potential error percentage based on the results of field survey and interview methods in Ardabil Province

\begin{tabular}{lcc}
\hline Village & Area (ha) & Annual harvest (ton) \\
\hline Hasanbaroogh & 2.181 & 4154 \\
Khodadoost & 6.576 & 5.432 \\
Gholibigloo & 0.008 & 0.426 \\
Kargan & 1.376 & 15.231 \\
Mazjin & 0.406 & 13.953 \\
Rahimbigloo & 7.127 & 59.648 \\
Average & 2.946 & 16.474 \\
Total & 6705.579 & 37495.55 \\
Error percentage & $22.065 \%$ & $15.926 \%$ \\
\hline
\end{tabular}

Note: the total number of villages of Ardabil equals 2276

\begin{tabular}{|c|c|c|}
\hline Village & Area (ha) & Annual harvest (ton) \\
\hline Cheghakabood & 0 & 0 \\
\hline Goharabad & 0.551 & 1.275 \\
\hline Kolyaii & 0 & 0 \\
\hline Sarabniloofari & 1.241 & 3.571 \\
\hline bedarban & 3.793 & 3.826 \\
\hline Barnaj & 4.241 & 22.959 \\
\hline Gorgindarreh & 0.172 & 0.765 \\
\hline Average & 1.428 & 4.628 \\
\hline Total & 3995.714 & 12945.7 \\
\hline Error percentage & $21.509 \%$ & $27.246 \%$ \\
\hline
\end{tabular}

Note: the total number of villages of Kermanshah equals 2797 
Figure 1: Geographical map of the studied provinces

(E: Eastern Azerbaijan, K: Kermanshah, A: Ardabil, Z: Zanjan)
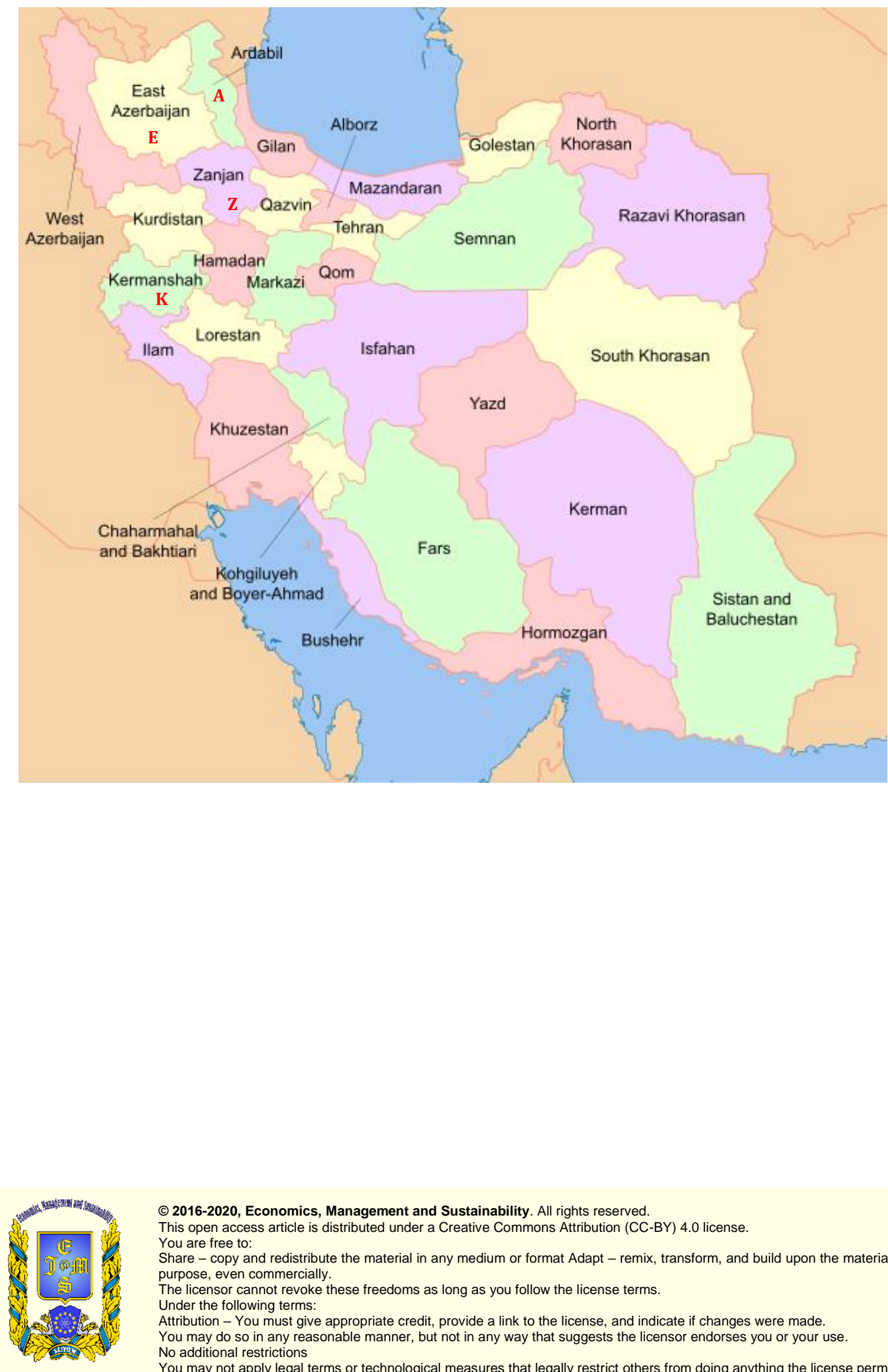

(c) 2016-2020, Economics, Management and Sustainability. All rights reserved.

This open access article is distributed under a Creative Commons Attribution (CC-BY) 4.0 license.

You are free to:

Share - copy and redistribute the material in any medium or format Adapt - remix, transform, and build upon the material for any

purpose, even commercially.

The licensor cannot revoke these freedoms as long as you follow the license terms.

Under the following terms:

Attribution - You must give appropriate credit, provide a link to the license, and indicate if changes were made.

You may do so in any reasonable manner, but not in any way that suggests the licensor endorses you or your use.

No additional restrictions

You may not apply legal terms or technological measures that legally restrict others from doing anything the license permits.

Economics, Management and Sustainability (ISSN: 2520-6303) is published by Scientific Publishing House "CSR",

Poland, EU and Scientific Publishing House "SciView", Poland

Publishing with JEMS ensures:

- Immediate, universal access to your article on publication

- High visibility and discoverability via the JEMS website

- Rapid publication

- Guaranteed legacy preservation of your article

- Discounts and waivers for authors in developing regions

Submit your manuscript to a JEMS at http://jems.sciview.net or submit.jems@sciview.net 